\title{
Chemical Composition and In Vitro Antiplasmodial Activity of the Total Alkaloids of the Bulbs of Two Amaryllidaceae Species from Northern Peru
}

\author{
Marilú Roxana Soto-Vásquez ${ }^{1, *}$, Madeleine Vanessa Horna -Pinedo ${ }^{1}$, Luciana R. Tallini² ${ }^{2}$ Jaume Bastida ${ }^{3}$
}

\author{
Marilú Roxana Soto-Vásquez ${ }^{1, *}$, \\ Madeleine Vanessa Horna \\ -Pinedo', Luciana R. Tallini', \\ Jaume Bastida ${ }^{3}$
}

'Facultad de Farmacia y Bioquímica. Universidad Nacional de Trujillo, Trujillo, PERU.

2Programa de Pós-Graduação em Ciências Farmacêuticas, Faculdade de Farmácia, Universidade Federal do Rio Grande do Sul, Av. Ipiranga 2752, Porto Alegre RS 90610000, BRAZIL.

${ }^{3}$ Departament de Biologia, Sanitat i Medi Ambient, Facultat de Farmàcia, Universitat de Barcelona, Av. Joan XXIII 27-31, 08028 Barcelona, SPAIN.

\section{Correspondence}

Dr. Marilú Roxana Soto-Vásquez

Facultad de Farmacia y Bioquímica. Universidad Nacional de Trujillo, Trujillo, PERU

Phone no: +51 954459817;

E-mail: msoto@unitru.edu.pe

History

- Submission Date: 02-04-2021;

- Review completed: 29-04-2021;

- Accepted Date: 07-06-2021.

DOI : 10.5530/pj.2021.13.135

Article Available online

http://www.phcogj.com/v13/i4

Copyright

(c) 2021 Phcogj.Com. This is an openaccess article distributed under the terms of the Creative Commons Attribution 4.0 International license.

\begin{abstract}
Introduction: The amaryllidaceae family is characterized by presenting alkaloids with powerful pharmacological activities, including antiprotozoal activity. The aim of the present work was to determine the chemical composition and evaluate the in vitro antiplasmodial activity of the total alkaloids of the bulbs of two amaryllidaceae species from northern Perú. Methods: The total alkaloids were extracted from the bulbs using an acid-base extraction. The chemical composition of the total alkaloids was determined by GC-MS, using galantamine as a reference standard. It was investigated the in vitro antiplasmodial activity against Plasmodium falciparum FCR-3 strain (chloroquine-resistant). Results: 8 alkaloids were identified in the bulbs of Clinanthus incarnatus: lycorine, galanthamine, galanthine, vittatine/crinine, hippamine, 3-O-acetylpowelline, 11,12-dehydroanhydrolycorine, 1-O-acetyllycorine with values of 19.73; 14.99; 10.36; 10.22; $10.16 ; 10.14 ; 10.04 ; 9.85 \mu \mathrm{g}$ GL/100 mg of total alkaloid (TA) respectively and 6 alkaloids in the bulbs of Clinanthus ruber: lycorine, anhydrolycorine, 11,12-dehydroanhydrolycorine, 2,4-didehydro-2-dehydroxylycorine, 8-0-dimethylmaritidine, hippamine, with values of 70.2; $18 ; 4.15 ; 3.45$ 6.8 and $0.1 \mu \mathrm{g} \mathrm{GAL} / 100 \mathrm{mg}$ TA respectively. The total alkaloids of the species of $C$. incarnatus and $C$. ruber at concentrations of $1.0 ; 2.5 ; 5.0 ; 10.0 ; 25.0$ and $50.0 \mu \mathrm{g} / \mathrm{ml}$ presented inhibition percentages of $23.5 \pm 0.46 \%$ to $94 \pm 0.56 \%$ against $P$. falciparum with $(p<0.05)$. They also presented $I C_{50} 0.375 \mu \mathrm{g} / \mathrm{ml}$ (C. incarnatus) and IC $0.241 \mu \mathrm{g} / \mathrm{ml}$ (C. ruber). Conclusion: The main component of total alkaloids of the bulbs of two species was lycorine, in adittion, these species showed in vitro antiplasmoidal activity against Plasmodium falciparum FCR-3 strain at the doses tested.
\end{abstract}

Key words: Clinanthus incarnatus, Clinanthus ruber, Plasmodium falciparum.

\section{INTRODUCTION}

Malaria is an infectious and life-threatening disease caused by Plasmodium parasites such as Plasmodium falciparum, Plasmodium ovale, Plasmodium vivax and Plasmodium malariae; Among these protozoa, P. falciparum is believed to be responsible for most serious diseases and most fatal cases ${ }^{1}$. In 2018, the World Health Organization (WHO) declared 228 million cases of malaria worldwide; mostly in the African Region, followed by the Eastern Mediterranean, Western Pacific and Southeast Asia; including 405,000 deaths ${ }^{2}$. To face this situation, WHO has recommended the use of therapies based on combinations of artemisinin and derivatives with other drugs; however, in some countries $P$. falciparum is already resistant to artemisinin combination therapies ${ }^{3}$.

The Global Technical Strategy for Malaria 20162030 defined the goal for 2030 to decrease the $90 \%$ of the incidence rate of malaria as well as related death rate ${ }^{4}$. To contribute with this purpose, we need to find new sources of medicaments against this illness. In this sense, plants are the main source of medicinal agents, even a large part of the world's population use herbs and it is not surprising to find a well-established system of traditional medicine in many countries ${ }^{5}$. The recognition and validation of traditional medicine is important and could lead to the discovery of new plant-derived drugs, such as quinine isolated from Cinchona species and artemisinin isolated from Artemisia annua $\mathrm{L}^{6}$. In addition, many compounds from various medicinal plants were isolated and showed in vitro and in vivo antiplasmodial activity against ${ }^{7}$.

The species Clinanthus incarnatus and Clinanthus ruber belong to the Amaryllidaceae family. This monocotyledonous botanical family is widely distributed throughout the world with approximately 70 genera and 1600 species. Besides there are 28 genera in South America and 24 genera in Peru, finding in this territory 138 species, among which are 15 to 20 species belonging to genus Clinanthus ${ }^{8}$.

Amaryllidaceae family plants contain, especially in the bulbs, a variety of unique alkaloids not present in other families. These isoquinoline alkaloids have powerful medicinal properties, including antitumor, antiviral, cytotoxic, acetylcholinesterase inhibitory, immunostimulating, anti-inflammatory, analgesic, and for the treatment of Alzheimer's disease 9 . Some of these alkaloids are of particular interest due to their potential antiprotozoal activity such as lycorine, agustinine and crinamine from Crinum amabile bulb, in addition, Haemanthamine and 6-hydroxyhaemanthamine exhibited antimalarial activity against chloroquine-sensitive and chloroquine-resistant strains of Plasmodium falciparum $^{10}$.

There are no previous reports on the species under study, so this research constitutes the first report in this regard. In this way, the objective of the research 
was to determine the chemical composition and evaluate the in vitro antiplasmodial activity of the total alkaloids of the bulbs of two amaryllidaceae species from northern Peru.

\section{MATERIALS AND METHODS}

\section{Collection of samples}

The bulbs of Clinanthus incarnatus (Kunth) Meerow and Clinanthus ruber (Herb.) Meerow \& A. Cano were collected from the districts of Otuzco (2641masl) and Pataz (3118 masl) in La Libertad Region. The botanical identification was carried out by Dr. Alan Meerow from Agricultural Research Service, United State Department of Agriculture, Miami, FL (USA), and deposited in the Herbarium Truxillense of the National University of Trujillo (HUT).

\section{Extraction of alkaloids}

The bulbs were washed, disinfected and cut into thin slices. Then they were dried in a forced convection oven at $40{ }^{\circ} \mathrm{C}$ for 72 hours. Once the plant material was completely dried, it was ground in a rotary blade mill. The dried powdered material was macerated with methanol for 72 hours at room temperature, applying ultrasonic baths at intervals of 1 to 2 hours. Subsequently, the methanolic extract was filtered and evaporated to dryness under reduced pressure using a rotary evaporator at a temperature of $40{ }^{\circ} \mathrm{C}$. The crude extract obtained was subjected to acidification with $\mathrm{H}_{2} \mathrm{SO}_{4}(2 \% \mathrm{v} / \mathrm{v})$ and was cleaned with ethyl ether, separating the organic phase composed of neutral materials such as chlorophylls, waxes and mucilages from the aqueous phase, rich in alkaloids. The acidic aqueous phase was subjected to basification with $\mathrm{NH}_{4} \mathrm{OH}(10 \% \mathrm{v} / \mathrm{v})$ until reaching a $\mathrm{pH}$ of 10 , then the alkaloids were extracted through the repeated use of chloroform, so that the alkaloids were retained in the organic phase. Then the solvent was evaporated under reduced pressure in the rotary evaporator at a temperature of 45 ${ }^{\circ} \mathrm{C}$, obtaining the extract of total alkaloids (TA $)^{11-13}$.

\section{GC-MS conditions}

Alkaloids were identified by using a GC-MS apparatus (Agilent Technologies $6890 \mathrm{~N}$ coupled with MSD5975 inert XL) operating in the electron ionization (EI) mode at $70 \mathrm{eV}$. A Sapiens-X5 MS column (30 $\mathrm{m} \times 0.25 \mathrm{~mm}$ i.d., film thickness $0.25 \mu \mathrm{m}$ ) was used. The temperature gradient was as follows: $12 \mathrm{~min}$ at $100{ }^{\circ} \mathrm{C}, 100-180^{\circ} \mathrm{C}$ at $15^{\circ} \mathrm{C} / \mathrm{min}$, $180-300{ }^{\circ} \mathrm{C}$ at $5^{\circ} \mathrm{C} / \mathrm{min}$ and $10 \mathrm{~min}$ hold at $300{ }^{\circ} \mathrm{C}$. The injector and detector temperatures were 250 and $280^{\circ} \mathrm{C}$, respectively, and the flowrate of carrier gas $(\mathrm{He})$ was $1 \mathrm{ml} / \mathrm{min}$. Two $\mathrm{mg}$ of each total alkaloids was dissolved in $1 \mathrm{ml}$ of $\mathrm{MeOH}: \mathrm{CHCl}_{3}(1: 1, \mathrm{v} / \mathrm{v})$ and $1 \mu \mathrm{l}$ was injected using the split-less mode. Codeine $(50 \mu \mathrm{g} / \mathrm{ml})$ was used as an internal standard.

\section{Alkaloid quantification}

To quantify the single constituents, a calibration curve of galanthamine $(10,20,40,60,80$ and $100 \mu \mathrm{g} / \mathrm{ml})$ was used. The same amount of codeine $(50 \mu \mathrm{g} / \mathrm{ml})$ was added to each sample as an internal standard. The peak areas were manually obtained considering selected ions for each compound (base peak of their MS, i.e., $\mathrm{m} / \mathrm{z}$ at 286 for galanthamine and 299 for codeine). The ratio between values obtained for galanthamine and codeine in each solution was plotted against the corresponding concentration of galanthamine to obtain the calibration curve and its equation $(y=0.0224 x-0.2037 ; R 2=0.9977)$. All data was standardized to the internal standard area (codeine) and the equation obtained for the calibration curve of galanthamine (GAL) was used to calculate the amount of each alkaloid. Results are expressed as $\mu \mathrm{g}$ GAL/ $100 \mathrm{mg}$ TA (total alkaloid).

\section{In vitro antiplasmodial activity}

The evaluation of the antiplasmodial activity of the total alkaloids was carried out in vitro with strain FCR3 (chloroquine resistant) of
Plasmodium falciparum, which were cultured in RPMI 1640 medium supplemented with $10 \%$ human serum and a hematocrit of $4 \%$ that was obtained adding $200 \mu \mathrm{l}$ of total red blood cells in $4.5 \mathrm{ml}$ of RPMI 1640 and $0.5 \mathrm{ml}$ of serum or plasma (Blood group $0, \mathrm{Rh}^{+}$) and incubated at $37^{\circ} \mathrm{C}$ in a $5 \% \mathrm{O}_{2} 6 \%$ gas mixture atmosphere of $\mathrm{CO}_{2}$ and balanced $\mathrm{N}_{2}$, as described by Trager $\mathrm{W}$, et al, with some modifications. The tests for the antiplasmodial activity of the total alkaloids (1.0, 2.5, 5.0, 10.0, 25.0 and $50.0 \mu \mathrm{g} / \mathrm{ml}$ dissolved in DMSO), were carried out in 96-well plates of flat bottom, for each alkaloidal extract in triplicate. Chloroquine diphosphate (10 to $1000 \mathrm{nM}$ ) was used as a control of the test. The cultures were synchronized with a parasitaemia and a hematocrit of 1 and $2 \%$ respectively; These were dispensed in a volume of $100 \mu \mathrm{l}$ in 96-well plates in duplicate, $100 \mu \mathrm{l}$ of the total alkaloids were added, and finally they were incubated at $37^{\circ} \mathrm{C}$ for 48 hours. After this incubation time, the upper phase of the culture was completely eliminated, to make a smear of the sediment from each well, then fixing with methanol and staining with Giemsa. These plates were observed under the microscope with a $100 \mathrm{x}$ immersion lens, counting uninfected red blood cells (GRL) and infected red blood cells (GRI), to obtain the percentage (\%) of Inhibition calculated by the formula ${ }^{14-16}$ :

$$
\% \text { inhibition }=\frac{(G R L-G R I)}{G R L} \times 100
$$

The $\mathrm{IC}_{50}$ value was calculated by an activity curve: Percentage of inhibition vs. logarithm of drug concentration, through linear interpolation calculation:

$\log (I C 50)=\log (X 1)+50-Y 1 / Y 2-Y 1[\log (X 2)-\log (X 1)]$

$\mathrm{X} 1=$ Concentration of the drug that gives an inhibition of $\mathrm{Y} 1$ parasitemia $>50 \%$;

$\mathrm{X} 2$ = Concentration of the drug giving an inhibition of $\mathrm{Y} 2$ parasitemia $<50 \%$;

$\mathrm{Y} 1$ = Percentage of inhibition of X1

$\mathrm{Y} 2=$ Percentage of inhibition of X2

\section{Statistic analysis}

The results were processed using the statistical program SPSS v. 23 and, expressed as the arithmetic median \pm standard deviation. The relationship between the groups was determined using the one-way ANOVA test, in which p 0.05 were considered statistically significant.

\section{RESULTS}

\section{Alkaloids Identified in C. incarnatus and C. ruber by GC-MS}

The identified alkaloids and their structures are represented in Table 1 and Figure1. The alkaloids present in the analyzed samples were identified by comparing their GC-MS spectra and Kovats retention index (RI) values with those of authentic Amaryllidaceae alkaloids previously isolated and identified by spectrometric methods (NMR, UV, CD, IR, MS) in the Natural Products Laboratory of Barcelona University, the NIST 05 Database, or literature data. The MS spectra were deconvoluted by AMDIS 2.64 software (NIST).

As can be seen in Table1 and Figure 1, 8 alkaloids were identified in the bulbs of Clinanthus incarnatus using GC-MS: lycorine (7), Galanthamine (11), galanthine(5), vittatine/crinine(8), hippamine(5), 3-O-acetylpowelline (9), 11,12-dehydroanhydrolycorine(3), $1-O$-acetyllycorine $(6)$ with values of $19.73 ; 14.99 ; 10.36 ; 10.22 ; 10.16$; $10.14 ; 10.04 ; 9.85 \mu \mathrm{g} \mathrm{GAL} / 100 \mathrm{mg}$ of TA respectively.

Approximately $87.5 \%$ of the identified alkaloids were of the lycorine type, $25 \%$ of the crinine/haemanthamine-type and $12.5 \%$ of the Galanthamine-type. Meanwhile in Clinanthus ruber bulbs, 6 alkaloids were 


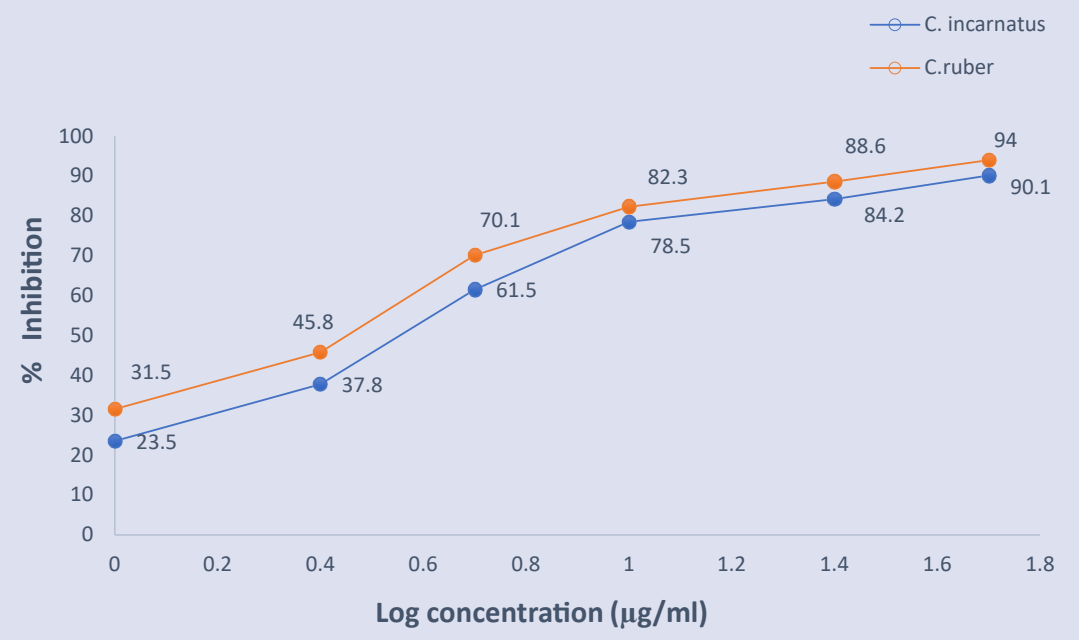

Figure 1: In vitro antiplasmodial activity of the total alkaloids of the bulbs of Clinanthus incarnatus and Clinanthus ruber.

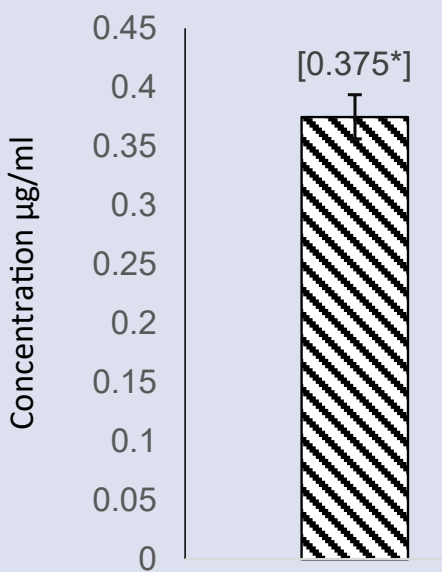

C. incarnatus

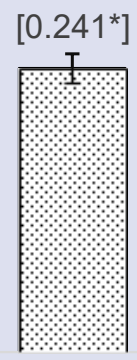

C. ruber $\left[0.046^{*}\right]$

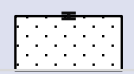

Cloroquine

Figure 2: $\mathrm{Cl}_{50}$ of the total alkaloids (TA) of the bulbs of Clinanthus incarnatus and Clinanthus ruber and cloroquine.

Table 1: Alkaloids identified in Clinanthus incarnatus and Clinanthus ruber by GC-MS. Values in $\mu \mathrm{g} \mathrm{GAL/100} \mathrm{mg} \mathrm{TA.}$

\begin{tabular}{|c|c|c|c|c|c|}
\hline Alkaloids & {$\left[\mathrm{M}^{+}\right]$} & $\begin{array}{c}\text { Rt } \\
(\mathrm{min})\end{array}$ & RI & C. incarnatus & C. ruber \\
\hline \multicolumn{6}{|l|}{ Lycorine-type } \\
\hline Anhidrolycorine (1) & 251 & 23.962 & 2501.6 & - & 18.0 \\
\hline 2,4-didehydro-2-dehydroxylycorine (2) & 269 & 24.451 & 2534.4 & - & 4.15 \\
\hline 11,12- dehydroanhydrolycorine (3) & 249 & 25.508 & 2653.2 & 10.04 & 5.81 \\
\hline Hippamine (4) & 301 & 26.514 & 2705.8 & 10.16 & $<0.1$ \\
\hline Galanthine (5) & 317 & 26.884 & 2730 & 10.36 & - \\
\hline 1-O-Acetyllycorine (6) & 329 & 27.142 & 2747.0 & 9.85 & - \\
\hline Lycorine (7) & 287 & 27.693 & 2783.1 & 19.73 & 70.2 \\
\hline \multicolumn{6}{|l|}{ Crinine/haemanthamine-type } \\
\hline Vittatine /crinine (8) & 271 & 23.660 & 2518.7 & 10.22 & - \\
\hline 3-O-acetylpowelline (9) & 343 & 25.370 & 2630.8 & 10.14 & \\
\hline 8-0-demethylmaritidine (10) & 273 & 28.327 & 2794.2 & - & 3.45 \\
\hline \multicolumn{6}{|l|}{ Galanthamine-type } \\
\hline Galanthamine (11) & 287 & 22,355 & 2433,2 & 14.99 & - \\
\hline \multicolumn{6}{|l|}{ Not identified } \\
\hline NI, m/z $201 ;[\mathrm{M}=273]^{*}(12)$ & 273 & 23.904 & 2497.8 & - & $<0.1$ \\
\hline NI, m/z 125 (homolycorine-type)* (13) & 125 & 29.419 & 2867.4 & - & 6.80 \\
\hline
\end{tabular}

* proposed structure-type according to the fragmentation pattern; Rt: retention time; RI:Kovats Retention Index; NI: not identified. 
<smiles>c1cc2c3c(c1)-c1cc4c(cc1CN3CC2)OCO4</smiles>

(1)<smiles>CO[C@H]1C=C2CCN3Cc4cc5c(cc4[C@H]([C@H]1O)[C@]23C)OCO5</smiles>

(4)<smiles>C[C@]12c3cc4c(cc3CN3CCC(=C[C@@H](O)C1O)C32)OCO4</smiles>

(7)<smiles>COc1c2c(cc3c1N1C[C@@H](OC(C)=O)CC[C@H]3C1)OCO2</smiles>

(9)<smiles></smiles>

(2)<smiles>COC1=CC2=CCN3Cc4cc(OC)c(OC)cc4[C@](O)(C23)[C@@H]1O</smiles>

(5)

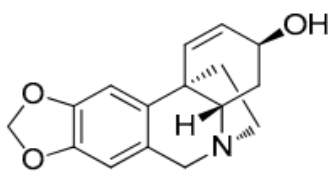

(8 a)<smiles>CC[C@]12C=C[C@@H](O)CCN1Cc1cc(O)c(OC)cc12</smiles>

(10)<smiles></smiles>

(3)<smiles>C[C@H](O)O[C@@H]1[C@H]2c3cc4c(cc3CN1CCC1=C[C@H](O)[C@@H]12)OCO4</smiles>

(6)<smiles>O[C@H]1C=CC23CC[C@@H](Cc4cc5c(cc41)OCO5)CN(C2)C3</smiles>

(8 b)<smiles>COc1ccc2c3c1O[C@H]3C[C@H](O)C=C[C@H]2CN(C)C</smiles>

(11)

Alkaloids identified in C. incarnatus and $C$. ruber by GC-MS. Anhidrolycorine (1), 2,4-didehydro-2-dehydroxylycorine (2), 11,12- dehydroanhydrolycorine (3), hippamine (4), galanthine (5), 1-O-acetyllycorine (6), lycorine (7), vittatine(8a)/crinine(8b), 3-O-acetylpowelline (9), 8-0-demethylmaritidine (10), galanthamine (11).

identified: lycorine(7), anhydrolycorine (1), 11,12-dehydroanhydrolycorine(3), 2,4-didehydro-2-dehydroxylycorine(2), 8-0-dimethylmaritidine(10), hippamine (4), with values of $70.2 ; 18 ; 5.81 ; 4.15 ; 3.45$ and $<0.1 \mu \mathrm{g}$ GAL / $100 \mathrm{mg}$ TA respectively; somehow, 2 alkaloids were not identified ( $\mathrm{m} / \mathrm{z} 201[\mathrm{M}+=273](12), \mathrm{m} / \mathrm{z} 125$ (homolycorine-type) (13), with values of $<0.1,6.80 \mu \mathrm{g}$ GAL $/ 100 \mathrm{mg}$ TA respectively. From $100 \%$ of alkaloids identified, $83 \%$ correspond to the lycorine type and $17 \%$ to the crinine/haemanthamine type.

Shows that there is a directly proportional relationship between the concentration of total alkaloids and the percentage of inhibition of the P. falciparum with values of $23.5 \pm 0.46 \%$ at $90.1 \pm 0.1 \%$ (C. incarnatus) and $31.5 \pm 0.1 \%$ at $94 \pm 0.56 \%$ (C.ruber). Besides, in figure 2 , the values of $\mathrm{IC}_{50} 0.375 \mu \mathrm{g} / \mathrm{ml}$ (C. incarnatus) and $\mathrm{IC}_{50} 0.241 \mu \mathrm{g} / \mathrm{ml}$ (C. ruber) are shown, indicating antiplasmodial activity. ANOVA and Tukey test were applied, determining that there is a statistically significant difference between the percentages of inhibition and $\mathrm{IC}_{50}$ values between both species and chloroquine $(\mathrm{p}<0.05)$

The data presented correspond to the average of three replications \pm standard deviation. The asterisks represent a significant difference in relation to the control (chloroquine) according to the ANOVA test ( $\mathrm{p}$ $<0.05)$.

\section{DISCUSSION}

The amaryllidaceae family is distinguished for its exclusive alkaloids isolated from all its genera ${ }^{17}$. Generally are isoquinoline type alkaloids that have not been identified in any other plant family and are classified into nine different types based on the heterocyclic system: norbelladine, lycorine, homolycorine, crinine, hemantamine, narcyclisine, tazetine, montanine and galantamine $e^{18,19}$.

In this sense, the alkaloids found in both species in this research belong to lycorine type as well as crinine/haemanthamine-type, founding that lycorine is the majority alkaloid in both species with values of $19.73 \mu \mathrm{g}$ GAL / $100 \mathrm{mg}$ TA ( 0.01973\%) and 70.2 $\mu \mathrm{g}$ GAL /100 mg TA $(0.0702 \%)$ respectively; what matches other investigations in amaryllidaceae species where concentrations ranged from $0.006 \%$ to $0.162 \%$ for Galanthus elwesii ${ }^{20}, 0.10-0.53 \%$ for Sternbergia sicula ${ }^{21}$, $0.19-0.40 \%$ for Sternbergia lutea ${ }^{21}$ and $0.05-0.14 \%$ for Pancratium maritimum $^{21}, 0.009 \%$ to $0.012 \%$ for Galanthus trojanus) $)^{22}$, and $0.004 \%$ for Galanthus cilicicus $^{22}$. It should be noted that the variability in the concentration depends on the environmental conditions and stress factors to which the plant is exposed ${ }^{20-22}$. Besides lycorine has a variety of biological activities (antineoplastic, immunostimulant, 
bacteriostatic, anticholinesterase, analgesic, anti-inflammatory, antiviral, antiprotozoal and antimalarial $)^{23}$.

The total alkaloids of the species of C. incarnatus and C. ruber at concentrations of $1 \mu \mathrm{g} / \mathrm{ml}, 2.5 \mu \mathrm{g} / \mathrm{ml}, 5 \mu \mathrm{g} / \mathrm{ml}, 10 \mu \mathrm{g} / \mathrm{ml}, 25 \mu \mathrm{g} / \mathrm{ml}$ and $50 \mathrm{ug} / \mathrm{ml}$ showed inhibition percentages from $23.5 \pm 0.46 \%$ at $90.1 \pm$ $0.1 \%$ (C. incarnatus) and $31.5 \pm 0.1 \%$ at $94 \pm 0.56 \%$ (C.ruber) against $P$. falciparum, obtaining the highest percentages at a concentration of 50 $\mu \mathrm{g} / \mathrm{ml}$ with values of $90.1 \pm 0.1 \%$ and $94 \pm 0.56 \%$ respectively. Besides these alkaloids presented values of $\mathrm{IC}_{50} 0.375 \mu \mathrm{g} / \mathrm{ml}$ (C. incarnatus) and $\mathrm{IC}_{50} 0.241 \mu \mathrm{g} / \mathrm{ml}$ (C. ruber), and when these results are compared with the criteria of the Research Initiative on Traditional Antimalarial Methods - RITAM, we found that they present a good level of activity ${ }^{24}$. In this context, some studies show that the alkaloids of the bulbs of the amaryllidaceae family present antiplasmodial activity in vitro against P. falciparum such as lycorine $\left(\mathrm{IC}_{50} 1.026 \mu \mathrm{g} / \mathrm{ml}\right)$, crinine $\left(\mathrm{IC}_{50} 2.110\right.$ $\mu \mathrm{g} / \mathrm{ml}$ ), haemantamine $\left(\mathrm{IC}_{50} 0.703 \mu \mathrm{g} / \mathrm{ml}\right)$, 6-hydroxyhaemantamine $\left(\mathrm{IC}_{50} 0.348 \mu \mathrm{g} / \mathrm{ml}\right), 3$-epihydroxybulbispermine $\left(\mathrm{IC}_{50} 1.139 \mu \mathrm{g} / \mathrm{ml}\right)$, galantamine $\left(\mathrm{IC}_{50} 4.38 \mu \mathrm{g} / \mathrm{ml}\right.$ ), tazzetine $\left(\mathrm{IC}_{50} 5.420 \mu \mathrm{g} / \mathrm{ml}\right.$ ), ismine $\left(\mathrm{IC}_{50}>10 \mu \mathrm{g} / \mathrm{ml}\right), 1-\mathrm{O}$-acetylcaranine $(3.21 \mu \mathrm{g} / \mathrm{ml}), 3$-O-acetylhamaine $(1.14 \mu \mathrm{g} / \mathrm{ml})$, bufanamine $\left(\mathrm{IC}_{50} 25.9 \mu \mathrm{g} / \mathrm{ml}\right)^{25,26}$. In addition, other amaylliadaceae alkaloids such as haemantamine, haemantidine, lycorine, 3-epihydroxybulbispermine, galantine and pancracine, also showed antimalarial activity against the chloroquine-resistant strain $\mathrm{K} 1$ of $P$. falciparum, with values of $\mathrm{IC}_{50}$ below $1 \mu \mathrm{g} / \mathrm{ml}^{27}$. Numerous investigations show that lycorine has many properties such as antiinflammatory, antibacterial, antitumor, antiviral and antimalarial, even it was discovered that lycorine is the most powerful alkaloid against Plasmodium falciparum. ${ }^{27,28}$ Analysis of the chemical structure and antimalarial activity of lycorine shows that the best antimalarial effect is achieved with derivatives of lycorine that have free hydroxyl groups at $\mathrm{C}-1$ and $\mathrm{C}-2$, or esterified as acetates or isobutyrates. Furthermore, some studies afirmn that C-2-C-3 double bond also plays an important role in the antiplasmodial effect of lycorine derivatives ${ }^{28,29}$. Besides, 1,2-O-diacetyllycorine, other lycorine type alkaloid showed a $\mathrm{IC}_{50}$ of $0.097 \mathrm{ug} / \mathrm{ml}$ against the F-32 $\operatorname{strain}^{30}$. In this way, amaryllidaceae alkaloids, in special, lycorine type alkaloids are an interesting and viable option for drug discovery in antimalarial field, constituing this work in the first report of in vitro antiplasmodial activity for these species, thus contributing to the worldwide need to find new natural sources with antiplasmoidal potential.

\section{CONCLUSION}

The main component of total alkaloids of the Bulbs of two Amaryllidaceae species from Northern Peru was lycorine, in adittion, these species showed antiplasmoidal activity in vitro against Plasmodium falciparum (strain FCR3 resistant to Chloroquine) at the doses tested.

\section{CONFLICTS OF INTEREST}

The authors declare no conflicts of interest

\section{ACKNOWLEDGMENT}

We thank the Fondo Nacional de Desarrollo Científico, Tecnológico y de Innovación Tecnológica (FONDECYT) del Consejo Nacional de Ciencia Tecnología e Innovación Tecnologica (CONCYTEC- Perú) Grants No $110-2018$ - FONDECYT, for financial support to this study. The authors thank the Programa Iberoamericano de Ciencia y Tecnología para el Desarrollo (CYTED) for providing the framework.

\section{REFERENCES}

1. Buffet PA, Safeukui I, Deplaine G, Brousse V, Prendki V, Thellier M, Turner GD, Mercereau-Puijalon O. The pathogenesis of Plasmodium falciparum malaria in humans: insights from splenic physiology. Blood. 2011;117(2):381-392
2. WHO. World Malarie Report 2019. Geneva: World Health Organization; 2019. Pp12-13.

3. WHO. Report on antimalarial drug efficacy, resistance and response: 10 years of surveillance (2010-2019). Geneva:World Health Organization; 2020. Pp.3-5.

4. WHO. Global Technical Strategy for Malaria 2016-2030. Geneva: World Health Organization; 2015. Pp.3-8.

5. Ashley E, Dhorda M, Fairhurst R, Amaratunga C, Lim P, Suon S, et al Spread of Artemisinin Resistance in Plasmodium falciparum Malaria. N Engl J Med. 2014 Jul 31; 371(5):411-23.

6. Ankrah NA, Nyarko AK, Addo PG, Ofosuhene M, Dzokoto C, Marley $E$, et al. Evaluation of efficacy and safety of a herbal medicine used for the treatment of malaria. Phytother Res. 2003 Jun; 17(6):697-701.

7. León B, Sagástegui A, Sánchez I, Zapata M, Meerow A y Cano A Amaryllidaceae endémicas del Perú. Rev. Peru. Biol. 2006; 13(2): 690-97.

8. Bastida J, Berkov S, Torras L, Belén N, De Andrade JP, Martínez V, et al. Chemical and biological aspects of Amaryllidaceae alkaloids. In:Muñoz D. Editor. Recent Advances in Pharmaceutical Sciences. Kerala India: Transworld Research Network, p. 65-100;2011.

9. Likhitwitayawuid K, Angerhofer CK, Chai H, Pezzuto JM, Cordell GA. Cytotoxic and antimalarial alkaloids from the bulbs of Crinum amabile. J. Nat. Prod. 1993;56 (8): 1331-1338.

10. Bastida, J.; Lavilla, R.; Viladomat, F. Chemical and biological aspects of Narcissus alkaloids. In The Alkaloids: Chemistry and Physiology; Cordell, G.A., Editor. Amsterdam, The Netherlands, Elsevier, p. 87$179 ; 2006$

11. Acosta K, Incaa A, Tallinib L, Osorio E, Roblesa J, Bastida J, et al; Alkaloids of Phaedranassa dubia (Kunth) J.F. Macbr. and Phaedranassa brevifolia Meerow (Amaryllidaceae) from Ecuador and its cholinesteraseinhibitory activity. S. African J. Bot.2021;136(1): 9199.

12. Tallini L,Torras-Claveria $L$, de Souza Borges W, Kaiser M, Viladomat F, Zuanazzi J, Bastida J. N-oxide alkaloids from Crinum amabile (Amaryllidaceae). Molecules. 2018; 23(6): 1277-1288.

13. Gonring-Salarini k, et al. In vitro Antiplasmodial Activities of Alkaloids Isolated from Roots of Worsleya procera (Lem.) Traub (Amaryllidaceae). J. Braz. Chem. Soc. 2019;30(8): 1624-1633.

14. Bilge Sener , Ilkay Orhan, Jutamad Satayavivad. Antimalarial activity screening of some alkaloids and the plant extracts from Amaryllidaceae. Phytother Res. 2003 Dec;17(10):1220-3.

15. Zofou D, Kuete V, Titanji VPK. Antimalarial and other antiprotozoal products from African medicinal plants. In: Kuete V, Editor. Medicinal Plant Research in Africa: Pharmacology and Chemistry. EEUU: Elsevier, p. 661-709; 2013.

16. Berkov S, Osorio E, Viladomat F, Bastida J. Chemodiversity, chemotaxonomy and chemoecology of Amaryllidaceae alkaloids. Alkaloids Chemistry and biology. 2020;83(1):113-185.

17. Ka S, Koirala M, Mérindol N, Desgagné-Penix I. Biosynthesis and Biological Activities of Newly Discovered Amaryllidaceae Alkaloids. Molecules.2020; 25(21): 4901-4928.

18. Guo Y, Pigni NB, Zheng Y, de Andrade JP, Torras-Claveria L, Borges Wde $S$, et al. Analysis of bioactive Amaryllidaceae alkaloid profiles in Lycoris species by GC-MS. Nat. Pro. Commun. 2014;9(8):1081-1087.

19. Habartováa k, Cahlíkováb L, Rezacovaá M, Haveleka R. The Biological Activity of Alkaloids from the Amaryllidaceae: From Cholinesterases Inhibition to Anticancer Activity. Nat. Pro. Commun. 2016; 11 (10): 1587-1594.

20. Ahmet E, Ceren E, Buket B, Mustafa A, Nehir U, Gulen I. Application of HPLC-DAD for the quantification of Lycorine in Galanthus elwesii Hook. Braz. J. Pharm. Sci. 2017;53(1):15063-15069 
21. Kaya GI, Cicek D, Sarikaya B, Onur MA, Somer NU. HPLC - DAD analysis of lycorine in Amaryllidaceae species. Nat. Pro. Commun. 2010:5(6):873-879.

22. Kaya GI, Polat DC, Sarikaya B, Onur MA, Somer NU. Quantititative determination of lycorine and galanthamine in Galanthus trojanus and G. cilicicus by HPLC-DAD. Nat Prod Commun. 2014 Aug;9(8):1157-8.

23. Seydou K, Koirala M, Mérindol N, Desgagné-Penix I. Biosynthesis and Biological Activities of Newly Discoveres Amaryllidaceae Alkaloids. Molecules. 2020:25(21):4901-4928

24. Bodeker G, Willcox M. The The First International Meeting of the Research Initiative on Traditional Antimalarial Methods (RITAM). J. Alter. Complement. Med. 2000 6(2):195-207

25. Tener B, Orhan I, Satayavivad J. Antimalarial Activity Screening of Some Alkaloids and the Plant Extracts from Amaryllidaceae. Phytother Res. 2003:17(10):1220-1223.
26. Osorio E, Robledo S, Bastida J. Alkaloids with antiprotozoal activity In The Alkaloids Chemistry and Biology. In: Cordell G, Editor. The Alkaloids: Chemistry and Biology. Amsterdam:The Netherlands, $p$. 113-190; 2008

27. Osorio E, Montoya G, Arango G. Alkaloidal Natural Products With Antiprotozoal Activity. RevistaVitae.2006;13(1):61-84.

28. Cao Z, Yang P, Zhou Q. Multiple biological functions and pharmacological effects of lycorine. Sci China Chem. 2013; 56(10): 1382-1391.

29. Nair J, Staden J. Antiplasmodial Studies Within the Plant Family Amaryllidaceae. Nat. Pro. Commun.2019; 14(9): 1-6.

30. Schwikkard S, Van Heerden FR. Antimalarial activity of plant metabolites. Nat. Prod. Rep. 2002 Dec;19(6):675-92.

\section{GRAPHICAL ABSTRACT}

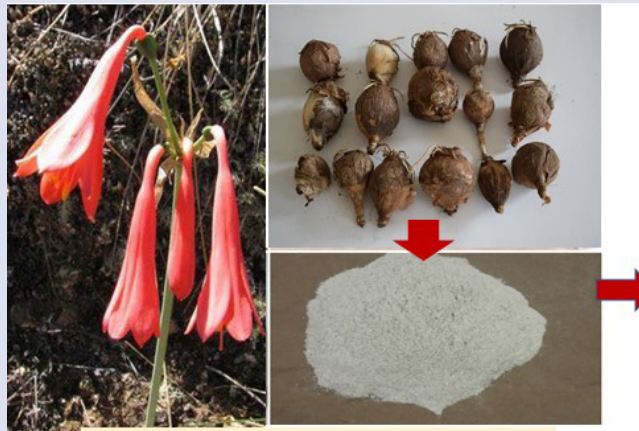

Clinanthus ruber

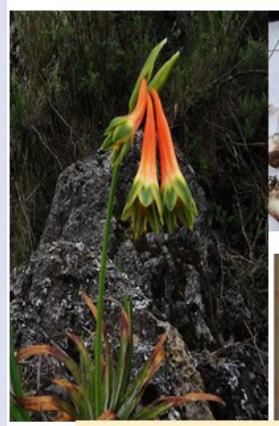

Clinanthus incarnatus
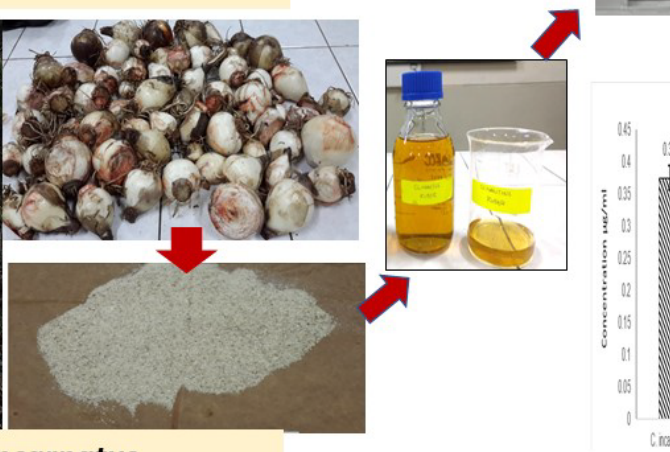

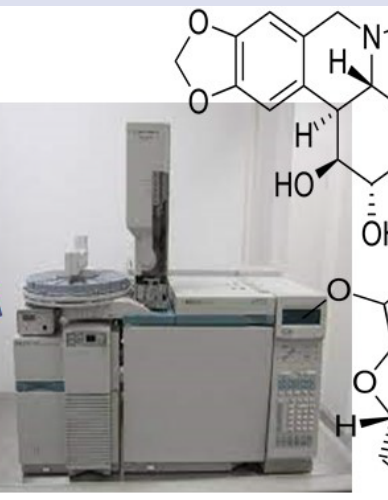
$\longrightarrow$ ÖH

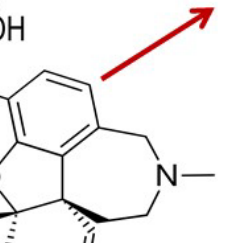
$\mathrm{HO}$

\section{Q

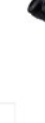

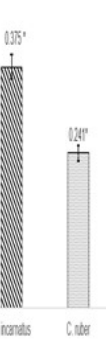

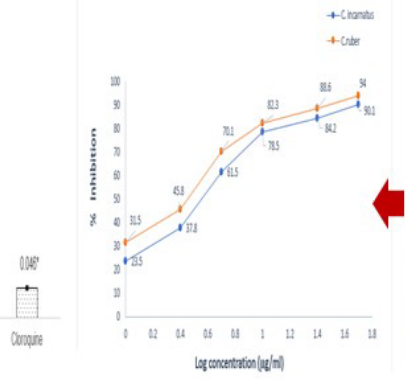




\section{ABOUT AUTHORS}

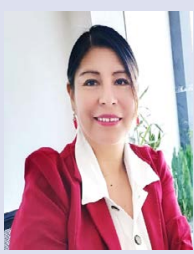

\section{Dr. Marilú Roxana Soto-Vásquez}

Doctor in Pharmacy and Biochemistry, professor of the chairs of pharmacognosy, phytochemistry, pharmaceutical botany of Faculty of Pharmacy and Biochemistry of Universidad Nacional de Trujillo. Develops Research in Natural Products with antiprotozoal, antitumor, antimicrobial activities, and Complementary and Alternative Medicine.

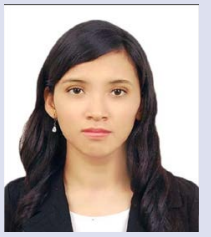

\section{Madeleine Vanessa Horna -Pinedo}

Bachelor of Pharmacy and Biochemistry of Universidad Nacional de Trujillo, Perú. Research Assistant in Natural Products.

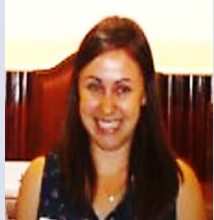

\section{Dr. Luciana R. Tallini}

Doctor in Research, Development and Control of Medicines at Universitat de Barcelona (Spain). She is currently doing a post-doctorate in the Graduate Program in Pharmaceutical Sciences at Universidade Federal do Rio Grande do Sul (UFRGS-Brazil), with experience in alkaloid isolation, capillary electrophoresis, HPLC, GC-MS, LC-MS, NMR. In addition, she has experience in in vitro biological tests.

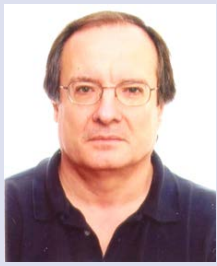

\section{Dr. Jaume Bastida}

Doctor in Pharmacy. Professor at Facultat de Farmàcia, Universitat de Barcelona (Spain), with extensive experience in isolation and characterization of natural products, and a great background in the study of the alkaloids of the Amaryllidaceae. Author of a patent about the production of the galantamine alkaloid validated for the European Union and North America.

Cite this article: Soto-Vásquez MR, Horna -Pinedo MV, Tallini LR, Bastida J. Chemical Composition and In Vitro Antiplasmodial Activity of the Total Alkaloids of the Bulbs of Two Amaryllidaceae Species from Northern Peru. Pharmacogn J. 2021;13(4): 10461052. 